\title{
Early sexual behaviour and Chlamydia trachomatis infection - a population based cross-sectional study on gender differences among adolescents in Norway
}

Kirsten Gravningen ${ }^{1,2^{*}}$, Anne-Sofie Furberg ${ }^{1,2}$, Gunnar Skov Simonsen ${ }^{1,3}$ and Tom Wilsgaard ${ }^{2}$

\begin{abstract}
Background: Early sexual behaviour has been shown to differ significantly between genders, but few studies have addressed this topic to explain the commonly observed differences in chlamydia rates between adolescent girls and boys. Our study aimed to determine chlamydia prevalence in adolescents aged 15-20 years in a high-incidence area in Norway, and to identify gender-specific early sexual behaviours associated with infection.

Methods: A population based cross-sectional study was conducted among all high school students in five towns in Finnmark county in 2009, using a web-based questionnaire and real-time Chlamydia trachomatis PCR in first-void urine samples (participation rate 85\%, 800 girls/818 boys, mean age 17.2 years). Crude and multivariable logistic regression models were applied with chlamydia test result as dependent variable.

Results: Prevalence of chlamydia infection was 5.7\% (95\% confidence interval, Cl, 4.4-7.3\%). Girls were twice as likely to be infected as boys (7.3\%, 5.3-9.7 vs 3.9\%, 2.3-6.0). Girls reported earlier sexual debut, older partners, higher lifetime number of partners, and were poorer condom users. In girls, higher maternal education (odds ratio, OR, $2.2,95 \% \mathrm{Cl} 1.1-4.4), \geq 2$ sexual partners past 6 months (OR 3.6, 1.8-7.3), and partner meeting venue at a private party, bar or disco (OR 5.0, 1.1-22.7) increased the odds of infection in the multivariable model. In boys, condom use at first intercourse (OR 0.06, 0.01-0.42) decreased the odds of infection, while having an older last sexual partner (OR 3.7, 1.3-11.0) increased the odds. In all participants, the risk of infection increased if residence outside the family home during school year (OR 2.0, 1.2-3.6), and decreased if condom was used at last intercourse (OR 0.2, 0.1-0.8).

Conclusions: We detected significant gender differences in chlamydia prevalence and sexual behaviours, and accordingly differing independent risk factors for chlamydia infection. We suggest that accumulation of essentially different experiences in the early sexually active years contribute to gender disparities in chlamydia risk in individuals this age. Gender-specific approaches may be the best alternative to control chlamydia infection in age group 15-20 years.
\end{abstract}

Keywords: Chlamydia trachomatis, Adolescent, Sexual behaviour, Gender differences, Cross-sectional study

\footnotetext{
* Correspondence: kirsten.gravningen@unn.no

'Department of Microbiology and Infection Control, pb 56, University

Hospital of North Norway, Tromsø N-9038, Norway

2Department of Community Medicine, Faculty of Health Sciences, University

of Tromsø, Tromsø N-9037, Norway

Full list of author information is available at the end of the article
} 


\section{Background}

Chlamydia trachomatis is the most commonly reported sexually transmitted infection (STI) in Europe and USA mainly affecting young individuals aged 15-24 years, and is more often diagnosed in adolescent females than in males [1,2]. The true incidence of chlamydia in both genders is assumed to be higher than the reported numbers as the majority of infections are asymptomatic [3].

Early heterosexual behaviour has been shown to differ significantly between genders in the Nordic countries [4], but few studies have addressed this topic to explain the commonly observed differences in chlamydia rates between adolescent girls and boys using biological samples. The higher chlamydia incidence rates among female adolescents in surveillance data has commonly been linked to more extensive testing of girls due to their health seeking behaviour and the fact that screening strategies and reproductive health services mainly target females $[1,5]$. However, several population based studies have also detected significantly higher chlamydia prevalences in adolescent girls than in same-aged boys [6-9]. This has mainly been attributed to girls being biologically more susceptible to chlamydia infections than boys, and also to increased exposure due to social and cultural factors $[5,8,10]$. In general, there is a lack of chlamydia studies in young adolescent boys as most research has focused on girls [5].

In 2009, Norway had the third highest chlamydia notification rate in Europe (474/100 000) [1]. A chlamydia incidence rate almost twice the national average has been reported in Finnmark, the northernmost and most sparsely populated county in Norway [11]. The population includes ethnic Norwegians, indigenous Sami people, and minority groups of Kvens, Finns, and Russians living together in small municipalities. The highest annual incidence rates in Finnmark among females were observed in the age group 15-19 years, while among males the infections peaked in the 20-24 year age group [12]. This age and gender distribution is similar to surveillance data from most other Western European countries [1].

In this study, we hypothesized that a significant reservoir of undetected infections might exist among the sexually active adolescents in Finnmark, and that they might exhibit high levels of sexual risk behaviours to explain why chlamydia has remained endemic in the area. Our aims were to detect chlamydia prevalence in adolescent girls and boys in a high-incidence rural area, and second, to examine gender-specific early sexual behaviours associated with chlamydia infections that might contribute to disproportionate infection rates in girls.

\section{Methods}

\section{Study population}

A population based cross-sectional study was conducted in five high schools in five towns in Finnmark county during fall 2009, reaching all high school students in these municipalities. In 2007-09, 94\% of the birth cohorts in Finnmark county were enrolled in public high school, with an annual drop-out rate of approximately 10\% [13]. This cross-sectional study was linked to a study on genetic diversity and distribution of $C$. trachomatis genotypes in the adolescent population in Norway. All chlamydia specimens had thus previously been genotyped using high resolution multilocus sequence typing, MLST [14].

Written information about the study in Norwegian and Sami was handed out in class by the teachers two weeks prior to data collection. All students regardless of sexual experience were invited to participate. From September $21^{\text {st }}$ to November $19^{\text {th }} 2009$, the same study doctor and nurse consecutively visited all 123 classes in the high schools. As shown in Figure 1, participation rate was $98 \%(1,618$ of 1,664$)$ among the eligible students, while overall participation rate was $85 \%(1,618$ of 1,908$)$. A urine sample was provided by $93 \%$ of those reporting ever having had sexual intercourse with no gender difference. Among 6 students with inconclusive test results, one girl testing negative one day prior to the study was assumed to have a negative result and was included in the analysis. 5 boys with an inconclusive test did not provide a new urine sample and were excluded. 1,031 sexually active students aged 15-20 years with a valid chlamydia test result were included in the final study sample. Mean age was 17.2 years (median 17.0, SD 1.0).

\section{Questionnaire}

On the day of data collection, a questionnaire designed in QuestBack online survey system (www.questback.com) was emailed class-wise to the students. All Norwegian high school students have laptop computers with internet access making implementation feasible. Under supervision of the study staff and a teacher, participants spent 1020 min completing the questionnaire which included questions on demography, sexual behaviour, alcohol and drug habits, prior chlamydia testing and treatment, and contraceptive use. Pre-programmed commands ensured automatic skipping of non-applicable questions. No reminders were sent.

\section{Urine sampling}

Directly thereafter, the participants went to the school toilets and provided first-void urine (FVU) samples under supervision of the nurse. The samples were immediately refrigerated and transported by National Mail Delivery on the same day to the University Hospital of North Norway, Tromsø, and analysed within $24 \mathrm{~h}$.

\section{Chlamydia PCR}

The laboratory extracted DNA using the BUGS'n BEADS TM-STI kit (NorDiag ASA, Oslo, Norway) and 


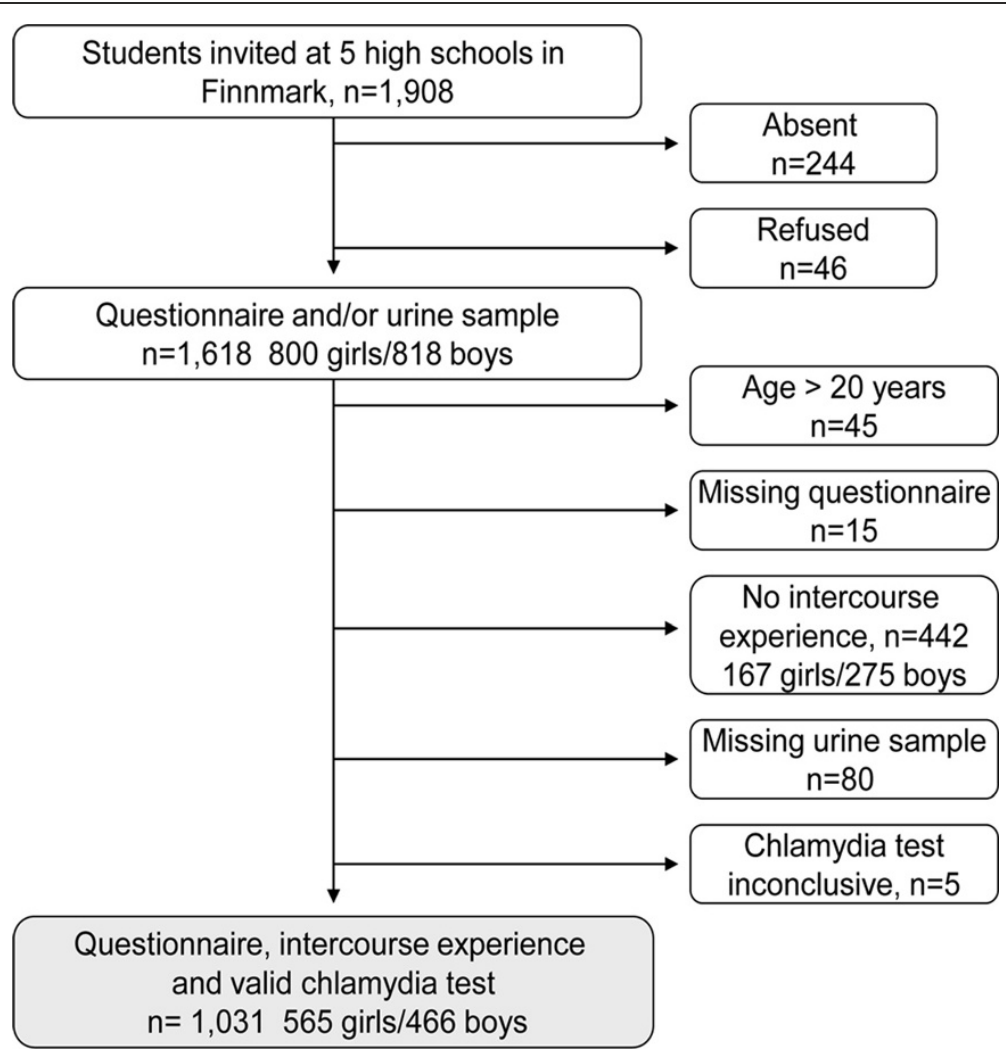

Figure 1 Study population.

used the ProCt real-time PCR (ProCelo as, Tromsø, Norway) with a sensitivity of $97 \%$ and a specificity of $100 \%$.

\section{Follow up}

Participants with a positive chlamydia test result were given an appointment at the local youth clinic. A single dose of one gram azithromycin orally was either prescribed or handed out directly.

\section{Sample size calculations}

We estimated a sample size of 974 to achieve $90 \%$ power to detect a difference between an anticipated chlamydia prevalence of $3.0 \%$ in the source population irrespective of sexual intercourse experience, compared to $1.4 \%$ as observed in a similar study in South Norway using a $5 \%$ significance level [6]. The anticipated prevalence was based on a pilot study in Finnmark (unpublished data).

\section{Data analysis}

Descriptive characteristics were reported with means (SD) for continuous variables and with numbers (\%) for categorical variables. The $95 \%$ confidence intervals $(\mathrm{CI})$ for proportions were calculated using the exact binominal method. Crude and multivariable logistic regression models were applied with chlamydia test result as dependent variable. Variables with $p$ value $<0.25$ in crude analysis were included in the multivariable models which were fitted using backward stepwise elimination. Age and gender (if applicable) were included regardless of significance. Collinearity was not a problem with variance inflation factor (VIF) $<2.5$ for all variables. Gender interaction was assessed by including cross-product terms between each independent variable and gender. All statistical tests were two-sided using a 5\% significance level and were performed in SPSS 19.0 (IBM Corp., New York, US).

Self-perceived ethnicity was coded in three categories based on the statement: 'I perceive my ethnicity as: Norwegian, Sami, Russian, Kven, Finnish, or other'. More than one answer was allowed. Category 'Norwegian' included those reporting Norwegian $(\mathrm{n}=726)$ and/or Kven $(n=5)$ ethnicity, as the two share a common distribution of life-style factors [15]. 'Sami/Sami-Norwegian' included those reporting Sami ethnicity $(\mathrm{n}=90)$ or both Sami and Norwegian ethnicity $(\mathrm{n}=139)$. 'Other' included Russian ( $n=19)$, Finn $(n=20)$ and other $(n=31)$ ethnicity.

Use of alcohol, cannabis, amphetamine or ecstasy was reported for each substance as: never tried (1), tried (2), occasional use (3), or regular use (4). A new variable 'alcohol/drug use' was calculated as sum of the four substance use variables. Participants with missing response for alcohol $(\mathrm{n}=5)$ were excluded, but missing was 
accepted for the other three. Range of the 'alcohol/drug use' variable was $2-16$, and was defined as: $\leq 5$ : 'low'; 6 : 'medium'; $\geq 7$ : 'high'.

Condom use at first intercourse with first partner and at last intercourse with last partner were coded in two categories (yes/no) based on the question: 'Did you use any kind of contraception at first (last) sexual intercourse?' with response alternatives: 1) No; 2) Condom; 3) Hormonal contraception; 4) IUD; 5) Both condom and other contraception; 6) Emergency pill; 7) Coitus interruptus; 8) Don't know. Category 'yes' included participants with responses 2 and 5. 'No' included the remaining responses. 'Don't know' was answered by 3 girls and 10 boys at first intercourse and by 3 girls and 8 boys at last intercourse.

\section{Ethics}

Written informed parental consent was obtained for participants $<16$ years. Participants $\geq 16$ years gave their informed consent by filling in the web-based questionnaire. The study was approved by the Regional Committee for Medical and Health Research Ethics North Norway.

\section{Results}

\section{Study sample}

Socio-demographic characteristics of the study population are given in Table 1. Only participants at risk, i.e. reporting ever having had sexual intercourse, were included. Most participants reported Norwegian ethnicity (71\%), while Sami/Sami-Norwegian was reported by $22 \%$. More girls than boys chose an academic discipline rather than vocational ( $61 \%$ vs $37 \%, p<0.001)$. Boys more frequently reported high level of substance use ( $28 \%$ vs $19 \%, p<0.001)$. Sexual debut at $\leq 14$ years was reported by $41 \%$ of girls and $34 \%$ of boys $(p=0.03)$ (Table 2). More girls than boys had been sexually active for $\geq 2$ years ( $73 \%$ vs $65 \%, p=0.003) .52 \%$ of girls and $36 \%$ of boys were currently in a steady relationship ( $p<$ 0.001 ). More girls than boys reported $\geq 6$ lifetime sexual partners ( $34 \%$ vs $25 \%, p=0.003)$. There was no gender difference in condom use at first intercourse, but more boys than girls reported condom use at last intercourse (34\% vs $16 \%, p<0.001)$. Condom use at first sexual intercourse significantly increased the odds of condom use at last intercourse with last partner in both girls and boys (odds ratio, OR, 3.4 vs odds ratio, OR, 7.5, $p=0.002)$. Last sexual partner $\geq 1$ year older was reported by $76 \%$ of girls and $12 \%$ of boys $(p<0.001)$. Average age of last partner was 19.8 years in girls and 16.4 years in boys $(p<0.001)$. One-fourth of participants met last sex partner at a private party, bar or disco (girls 23\%, boys $25 \%, p=0.34$ ). More boys than girls had used alcohol or illicit drugs in connection with last intercourse ( $24 \%$ vs
$18 \%, p=0.03)$. Girls were more likely than boys to have had a chlamydia test prior to the study ( $56 \%$ vs $21 \%, p<$ $0.001)$, and to have received chlamydia treatment $(20 \%$ vs $7 \%, p<0.001)$.

\section{Prevalence}

C. trachomatis prevalence was $5.7 \%$, in girls $7.3 \%$, and in boys $3.9 \%$ (Table 1). This gives a prevalence of $4.1 \%$ (95\% CI 3.3-5.3) in all participants irrespective of sexual intercourse experience. There were no statistically significant differences between the 5 schools. All participants with a positive test result reported sexual intercourse experience.

\section{Crude analyses}

The following factors significantly increased the odds of infection in girls: Sami-Sami-Norwegian ethnicity, mothers education $\geq$ college, $\geq 2$ sexual partners past 6 months, $\geq 6$ lifetime sexual partners, and meeting last partner at a private party, bar or disco (Tables 1 and 2). In boys, no condom use at first intercourse, no condom use with the most recent partner, and last sexual partner $\geq 1$ year older increased the odds of chlamydia. Interaction was observed between gender and condom use at first intercourse $(p=0.003)$, and was borderline significant for gender and maternal educational $\geq$ college $(p=$ 0.094).

Assessing all participants, the following additional factors increased the odds of infection in crude analyses: female gender (OR 1.93, 95\% CI 1.09-3.41), residence outside the family home in school year, and medium or high use of alcohol and illicit drugs.

\section{Multivariable logistic regression analysis}

Among girls, mother's education $\geq$ college, $\geq 2$ sexual partners past 6 months, and meeting last sexual partner at a private party, bar or disco increased the likelihood of infection (Table 3). In boys, condom use at first intercourse with first partner decreased the odds of chlamydia while last sexual partner $\geq 1$ year older increased the odds. In all participants, to have residence outside the family home, $\geq 2$ sexual partners past 6 months, meeting last sexual partner at a private party, bar or disco, and condom use at last intercourse were significant.

\section{Discussion}

We detected a substantial burden of chlamydia infections with a twofold higher prevalence in girls than in boys and with the infections beginning to be acquired soon after sexual initiation. The girls started to have sexual intercourse at younger age, had older partners, more frequently were in steady relationships, and reported higher numbers of lifetime partners than the boys. The 
Table 1 Sosio-demographic characteristics, prevalence and crude odds ratios for C. trachomatis infection in univariable logistic regression analysis

\begin{tabular}{|c|c|c|c|c|c|c|c|c|c|c|c|c|c|c|c|c|c|}
\hline \multirow[t]{2}{*}{ Characteristic } & \multicolumn{7}{|c|}{ Girls } & \multicolumn{7}{|c|}{ Boys } & \multicolumn{3}{|c|}{ Both } \\
\hline & $\mathrm{N}$ & (\%) & $\mathrm{n}_{\mathrm{CT}}$ & $(\%)$ & OR & $95 \% \mathrm{Cl}$ & $p^{7}$ & $\mathrm{~N}$ & $(\%)$ & $\mathrm{n}_{\mathrm{CT}}$ & $(\%)$ & OR & $95 \% \mathrm{Cl}$ & $p^{1}$ & OR & $95 \% \mathrm{Cl}$ & $p^{1}$ \\
\hline Total & 565 & $(100.0)$ & 41 & $(7.3)$ & & & & 466 & $(100.0)$ & 18 & (3.9) & & & & & & \\
\hline \multicolumn{18}{|l|}{ Age } \\
\hline 16 & 168 & $(29.7)$ & 11 & (6.5) & 1.00 & & 0.48 & 139 & $(29.8)$ & 3 & $(2.2)$ & 1.00 & & 0.38 & 1.00 & & 0.21 \\
\hline 17 & 177 & $(31.3)$ & 15 & $(8.5)$ & 1.32 & 0.59 to 2.97 & & 179 & $(38.4)$ & 9 & $(5.0)$ & 2.40 & 0.64 to 9.04 & & 1.51 & 0.76 to 3.00 & \\
\hline 18 & 166 & (29.4) & 9 & (5.4) & 0.82 & 0.33 to 2.03 & & 106 & (22.7) & 3 & $(2.8)$ & 1.32 & 0.26 to 6.68 & & 0.97 & 0.44 to 2.13 & \\
\hline $19-20$ & 48 & (9.6) & 6 & $(11.1)$ & 1.78 & 0.63 to 5.08 & & 39 & $(9.0)$ & 3 & (7.1) & 3.49 & 0.68 to 17.97 & & 2.17 & 0.91 to 5.17 & \\
\hline
\end{tabular}

\section{Family and culture}

Ethnicity

\begin{tabular}{|c|c|c|c|c|c|c|c|c|c|c|c|c|c|c|c|c|c|}
\hline Norwegian & 402 & $(71.2)$ & 23 & (5.7) & 1.00 & & 0.093 & 325 & $(70.0)$ & 12 & (3.7) & 1.00 & & 0.73 & 1.00 & & 0.21 \\
\hline Sami/Sami-Norwegian & 124 & $(21.9)$ & 14 & $(11.3)$ & 2.10 & 1.04 to 4.21 & & 105 & (22.6) & 3 & (2.9) & 0.74 & 0.21 to 2.77 & & 1.59 & 0.87 to 2.89 & \\
\hline Other & 39 & (6.9) & 4 & $(10.3)$ & 1.88 & 0.61 to 5.75 & & 34 & (7.3) & 2 & (5.9) & 1.63 & 0.35 to 7.61 & & 1.77 & 0.72 to 4.36 & \\
\hline \multicolumn{18}{|l|}{ Church affiliation ${ }^{2}$} \\
\hline Yes & 448 & $(79.6)$ & 33 & $(7.4)$ & 1.00 & & 0.88 & 294 & $(63.5)$ & 12 & $(4.1)$ & 1.00 & & 0.54 & 1.00 & & 0.36 \\
\hline No & 115 & $(20.4)$ & 8 & $(7.0)$ & 0.94 & 0.42 to 2.10 & & 169 & $(36.5)$ & 5 & (3.0) & 0.72 & 0.25 to 2.07 & & 0.74 & 0.40 to 1.40 & \\
\hline \multicolumn{18}{|l|}{ Residence in school year } \\
\hline At home & 356 & $(63.1)$ & 20 & (5.6) & 1.00 & & 0.051 & 287 & $(61.7)$ & 7 & (2.4) & 1.00 & & 0.084 & 1.00 & & 0.01 \\
\hline Other $^{3}$ & 208 & (36.9) & 21 & $(10.1)$ & 1.89 & 1.00 to 3.57 & & 178 & (38.3) & 10 & (5.6) & 2.38 & 0.89 to 6.37 & & 2.00 & 1.17 to 3.4 & \\
\hline \multicolumn{18}{|l|}{ Mother's education } \\
\hline$\leq$ High school/don't know & 313 & $(55.5)$ & 15 & $(4.8)$ & 1.00 & & 0.013 & 304 & $(65.7)$ & 12 & (3.9) & 1.00 & & 0.66 & 1.00 & & 0.03 \\
\hline$\geq$ College & 251 & $(44.5)$ & 26 & (10.4) & 2.30 & 1.19 to 4.44 & & 159 & (34.3) & 5 & (3.1) & 0.79 & 0.27 to 2.28 & & 1.79 & 1.05 to 3.04 & \\
\hline
\end{tabular}

\section{High school}

Study category

\begin{tabular}{|c|c|c|c|c|c|c|c|c|c|c|c|c|c|c|c|c|c|}
\hline Academic & 347 & $(61.4)$ & 21 & $(6.1)$ & 1.00 & & 0.17 & 171 & $(36.8)$ & 6 & (3.5) & 1.00 & & 0.90 & 1.00 & & 0.56 \\
\hline$\underline{\text { Vocational }}$ & 218 & $(38.6)$ & 20 & $(9.2)$ & 1.57 & 0.83 to 2.97 & & 294 & $(63.2)$ & 11 & $(3.7)$ & 1.07 & 0.39 to 2.94 & & 1.17 & 0.69 to 1.99 & \\
\hline \multicolumn{18}{|l|}{ Year } \\
\hline 1 & 210 & $(37.2)$ & 16 & (7.6) & 1.00 & & 0.68 & 178 & (38.3) & 4 & $(2.2)$ & 1.00 & & 0.44 & 1.00 & & 0.83 \\
\hline 2 & 198 & $(35.0)$ & 16 & $(8.1)$ & 1.07 & 0.52 to 2.19 & & 209 & $(44.9)$ & 9 & $(4.3)$ & 1.96 & 0.59 to 6.47 & & 1.20 & 0.66 to 2.21 & \\
\hline 3 & 157 & $(27.8)$ & 9 & (5.7) & 0.74 & 0.32 to 1.72 & & 78 & (16.8) & 4 & $(5.1)$ & 2.35 & 0.57 to 9.65 & & 1.08 & 0.53 to 2.21 & \\
\hline \multicolumn{18}{|c|}{ Alcohol/drug use } \\
\hline Low & 134 & $(23.8)$ & 4 & (3.0) & 1.00 & & 0.098 & 130 & $(28.4)$ & 3 & $(2.3)$ & 1.00 & & 0.087 & 1.00 & & 0.034 \\
\hline Medium & 322 & $(57.3)$ & 27 & (8.4) & 2.98 & 1.02 to 8.67 & & 198 & $(43.3)$ & 5 & $(2.5)$ & 1.10 & 0.26 to 4.67 & & 2.41 & 1.05 to 5.53 & \\
\hline High & 106 & (18.9) & 10 & (9.4) & 3.39 & 1.03 to 11.12 & & 129 & (28.2) & 9 & (7.0) & 3.18 & 0.84 to 12.01 & & 3.23 & 1.33 to 7.83 & \\
\hline
\end{tabular}

$n_{C T}$ number of chlamydia cases, $O R$ odds ratio, $C l$ confidence interval, ${ }^{1} p$-value for equality between categories; ${ }^{2}$ Affiliation to any denomination: Church of Norway ( $\left.n=722\right)$, Russian Orthodox Church ( $n=9$ ), Jehova's Witnesses/Pentecostals $(n=7)$, Islam $(n=4){ }^{3}$ Living with relatives, in students' houses or in private accommodation. 
Table 2 Sexual behaviour, prevalence and crude odds ratios for $C$. trachomatis infection in univariable logistic regression analysis

\section{Characteristic}

$$
\text { Girls }
$$

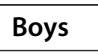

\section{Sexual behaviour}

Age at first intercourse

\begin{tabular}{|c|c|c|c|c|c|c|c|c|c|c|c|c|c|c|c|c|c|}
\hline$\geq 15$ years & 330 & $(58.8)$ & 24 & $(7.3)$ & 1.00 & & 0.97 & 294 & (65.9) & 8 & $(2.7)$ & 1.00 & & 0.10 & 1.00 & & 0.27 \\
\hline$\leq 14$ years & 231 & $(41.2)$ & 17 & (7.4) & 1.01 & 0.53 to 1.93 & & 152 & $(34.1)$ & 9 & (5.9) & 2.25 & 0.85 to 5.96 & & 1.35 & 0.79 to 2.30 & \\
\hline \multicolumn{18}{|c|}{ Years sexually active } \\
\hline$\leq 1$ year & 149 & (26.6) & 10 & (6.7) & 1.00 & & 0.74 & 158 & (35.4) & 2 & $(1.3)$ & 1.00 & & 0.055 & 1.00 & & 0.099 \\
\hline$\geq 2$ years & 412 & $(73.4)$ & 31 & $(7.5)$ & 1.13 & 0.54 to 2.37 & & 288 & (64.6) & 15 & $(5.2)$ & 4.29 & 0.97 to 18.99 & & 1.73 & 0.90 to 3.31 & \\
\hline \multicolumn{18}{|c|}{ Condom use first intercourse } \\
\hline $\mathrm{No}^{2}$ & 223 & (39.6) & 14 & $(6.3)$ & 1.00 & & 0.46 & 206 & $(45.3)$ & 16 & $(7.8)$ & 1.00 & & 0.003 & 1.00 & & 0.13 \\
\hline Yes & 340 & $(60.4)$ & 27 & (7.9) & 1.29 & 0.66 to 2.51 & & 249 & $(54.7)$ & 1 & $(0.4)$ & 0.05 & 0.01 to 0.36 & & 0.75 & 0.39 to 1.13 & \\
\hline \multicolumn{18}{|c|}{ Currently in a relationship } \\
\hline Yes & 296 & $(52.4)$ & 19 & (6.4) & 1.00 & & 0.42 & 167 & (35.8) & 6 & (3.6) & 1.00 & & 0.82 & 1.00 & & 0.69 \\
\hline No & 269 & $(47.6)$ & 22 & (8.2) & 1.30 & 0.69 to 2.46 & & 299 & $(64.2)$ & 12 & $(4.0)$ & 1.12 & 0.41 to 3.05 & & 1.12 & 0.66 to 1.90 & \\
\hline \multicolumn{18}{|c|}{ Sex partners past 6 months } \\
\hline $0-1$ & 323 & $(57.9)$ & 12 & (3.7) & 1.00 & & $<0.001$ & 254 & (58.8) & 6 & $(2.4)$ & 1.00 & & 0.053 & 1.00 & & $<0.001$ \\
\hline$\geq 2$ & 235 & $(42.1)$ & 29 & $(12.3)$ & 3.65 & 1.82 to 7.31 & & 178 & $(41.2)$ & 11 & $(6.2)$ & 2.72 & 0.99 to 7.50 & & 3.33 & 1.88 to 5.90 & \\
\hline \multicolumn{18}{|c|}{ Lifetime no of sex partners } \\
\hline $1-2$ & 192 & $(34.5)$ & 6 & $(3.1)$ & 1.00 & & 0.002 & 203 & $(47.8)$ & 4 & $(2.0)$ & 1.00 & & 0.24 & 1.00 & & $<0.001$ \\
\hline $3-5$ & 178 & (32.0) & 11 & $(6.2)$ & 2.04 & 0.74 to 5.64 & & 117 & (27.5) & 4 & (3.4) & 1.76 & 0.43 to 7.18 & & 2.06 & 0.91 to 4.66 & \\
\hline$\geq 6$ & 186 & (33.5) & 24 & (12.9) & 4.59 & 1.83 to 11.51 & & 105 & (24.7) & 6 & (5.7) & 3.02 & 0.83 to 10.93 & & 4.43 & 2.13 to 9.21 & \\
\hline
\end{tabular}

\section{Last sexual partner}

Age difference

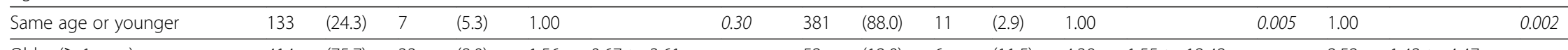

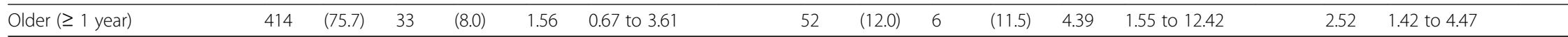

How met last partner

\begin{tabular}{lllllllllllllll}
\hline At school/work & 66 & $(11.7)$ & 2 & $(3.0)$ & 1.00 & 0.008 & 104 & $(23.0)$ & 2 & $(1.9)$ & 1.00 & 0.65 & 1.00 & \\
\hline
\end{tabular}

\begin{tabular}{lllllllllllllll}
\hline Through family/friends/other & 312 & $(55.4)$ & 16 & $(5.1)$ & 1.73 & 0.39 to 7.71 & 187 & $(41.4)$ & 4 & $(4.2)$ & 1.98 & 0.40 to 9.73 & 2.01 & 0.68 to 5.89 \\
\hline On the & & &
\end{tabular}

\begin{tabular}{lllllllllllllll}
\hline On the Internet & 58 & $(10.3)$ & 5 & $(8.6)$ & 3.02 & 0.56 to 16.19 & 47 & $(10.4)$ & 2 & $(4.3)$ & 2.27 & 0.31 to 16.60 & 2.96 & 0.85 to 10.38
\end{tabular}

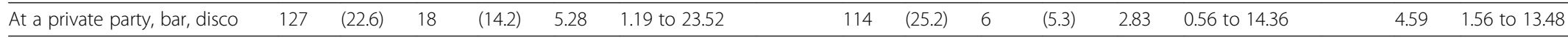

Type of relationship

\begin{tabular}{|c|c|c|c|c|c|c|c|c|c|c|c|c|c|c|c|c|c|}
\hline Regular partner/sweetheart & 324 & $(57.4)$ & 20 & $(6.2)$ & 1.00 & & 0.31 & 209 & $(46.3)$ & 5 & (2.4) & 1.00 & & 0.090 & 1.00 & & 0.51 \\
\hline Ex partner/sweetheart & 74 & $(13.1)$ & 8 & $(10.8)$ & 1.84 & 0.78 to 4.36 & & 51 & $(11.3)$ & 1 & $(2.0)$ & 0.82 & 0.093 to 7.14 & & 1.58 & 0.72 to 3.47 & \\
\hline A friend I have sex with & 103 & (18.3) & 6 & (5.8) & 0.94 & 0.37 to 2.41 & & 95 & (21.1) & 8 & $(8.4)$ & 3.75 & 1.19 to 11.79 & & 1.55 & 0.79 to 3.04 & \\
\hline Casual contact/other & 63 & $(11.2)$ & 7 & $(11.1)$ & 1.91 & 0.77 to 4.71 & & 96 & (21.3) & 3 & (3.1) & 1.32 & 0.31 to 5.62 & & 1.36 & 0.64 to 2.90 & \\
\hline
\end{tabular}


Table 2 Sexual behaviour, prevalence and crude odds ratios for C. trachomatis infection in univariable logistic regression analysis (Continued)

\begin{tabular}{|c|c|c|c|c|c|c|c|c|c|c|c|c|c|c|c|c|c|}
\hline Last & & & & & & & & & & & & & & & & & \\
\hline \multicolumn{18}{|c|}{ Condom use } \\
\hline $\mathrm{No}^{3}$ & 474 & (84.0) & 39 & $(8.2)$ & 1.00 & & 0.062 & 300 & $(66.5)$ & 16 & (5.3) & 1.00 & & 0.039 & 1.00 & & 0.003 \\
\hline Yes & 90 & $(16.0)$ & 2 & $(2.2)$ & 0.25 & 0.06 to 1.07 & & 151 & $(33.5)$ & 1 & $(0.7)$ & 0.12 & 0.02 to 0.90 & & 0.17 & 0.05 to 0.53 & \\
\hline \multicolumn{18}{|c|}{ Related alcohol/drug use } \\
\hline No & 460 & $(81.7)$ & 30 & $(6.5)$ & 1.00 & & 0.15 & 343 & $(76.2)$ & 11 & $(3.2)$ & 1.00 & & 0.26 & 1.00 & & 0.10 \\
\hline Yes & 103 & $(18.3)$ & 11 & $(10.7)$ & 1.71 & 0.83 to 3.54 & & 107 & (23.8) & 6 & (5.6) & 1.79 & 0.65 to 4.97 & & 1.64 & 0.91 to 2.94 & \\
\hline
\end{tabular}

\section{Chlamydia infection}

Test prior to study

\begin{tabular}{|c|c|c|c|c|c|c|c|c|c|c|c|c|c|c|c|c|c|}
\hline No & 251 & $(45.5)$ & 18 & $(7.2)$ & 1.00 & & 0.94 & 368 & $(79.1)$ & 11 & (3.0) & 1.00 & & 0.14 & 1.00 & & 0.11 \\
\hline Yes & 313 & $(55.5)$ & 23 & (7.3) & 1.03 & 0.54 to 1.95 & & 97 & $(20.9)$ & 6 & $(6.2)$ & 2.14 & 0.77 to 5.94 & & 1.55 & 0.91 to 2.63 & \\
\hline \multicolumn{18}{|c|}{ Treatment for infection } \\
\hline$\overline{\text { No }}$ & 452 & $(80.1)$ & 30 & (6.6) & 1.00 & & 0.25 & 433 & (93.3) & 16 & (3.7) & 1.00 & & 0.87 & 1.00 & & 0.13 \\
\hline Yes & 112 & (19.9) & 11 & (9.8) & 1.53 & 0.74 to 3.16 & & 31 & (6.7) & 1 & (3.2) & 0.87 & 0.11 to 6.78 & & 1.67 & 0.86 to 3.24 & \\
\hline
\end{tabular}

$\mathrm{n}_{\mathrm{C}}$, number of chlamydia cases, OR, odds ratio, $\mathrm{Cl}$, confidence interval, ${ }^{1} \mathrm{p}$-value for equality between categories, ${ }^{2}$ Includes the response: 'Uncertain if any contraception was used' (girls $\mathrm{n}=3$, boys $\mathrm{n}=10$ ), ${ }^{3} \mathrm{Includes}$ the response: 'Uncertain if any contraception was used' (girls $n=3$, boys $n=8$ ). 
Table 3 Odds ratios for C. trachomatis infection in multivariable logistic regression models

\begin{tabular}{|c|c|c|c|c|c|c|c|c|c|}
\hline \multirow[t]{2}{*}{ Characteristic } & \multicolumn{3}{|c|}{ Girls } & \multicolumn{3}{|c|}{ Boys } & \multicolumn{3}{|c|}{ Both } \\
\hline & OR & $95 \% \mathrm{Cl}$ & $p^{7}$ & OR & $95 \% \mathrm{Cl}$ & $p^{1}$ & OR & $95 \% \mathrm{Cl}$ & $p^{1}$ \\
\hline \multicolumn{10}{|l|}{ Family and culture } \\
\hline \multicolumn{10}{|l|}{ Residence in school year } \\
\hline At home & - & & & - & & & 1.00 & & 0.013 \\
\hline Other $^{2}$ & - & & & - & & & 2.04 & $1.17-3.57$ & \\
\hline \multicolumn{10}{|l|}{ Mother's education } \\
\hline SHigh school/don't know & 1.00 & & 0.021 & - & & & - & & \\
\hline$\geq$ College & 2.22 & $1.13-4.37$ & & - & & & - & & \\
\hline \multicolumn{10}{|l|}{ Sexual behaviour } \\
\hline \multicolumn{10}{|l|}{ Condom use first intercourse } \\
\hline No & - & & & 1.00 & & 0.005 & - & & \\
\hline Yes & - & & & 0.06 & $0.01-0.42$ & & - & & \\
\hline \multicolumn{10}{|l|}{ Sex partners past 6 months } \\
\hline $0-1$ & 1.00 & & $<0.001$ & - & & & 1.00 & & $<0.001$ \\
\hline$\geq 2$ & 3.59 & $1.76-7.32$ & & - & & & 2.88 & $1.60-5.18$ & \\
\hline
\end{tabular}

Last sexual partner

Age difference

\begin{tabular}{|c|c|c|c|c|c|c|c|c|c|}
\hline Same age or younger & - & & & 1.00 & & 0.017 & - & & \\
\hline Older ( $\geq 1$ year) & - & & & 3.74 & $1.27-11.01$ & & - & & \\
\hline \multicolumn{10}{|l|}{ How met last partner } \\
\hline At school/work & 1.00 & & 0.038 & & & & 1.00 & & 0.026 \\
\hline Through family/friends/other & 1.90 & $0.42-8.65$ & & - & & & 1.61 & $0.54-4.82$ & \\
\hline On the Internet & 3.40 & $0.62-18.78$ & & - & & & 2.81 & $0.78-0.08$ & \\
\hline At a private party, bar, disco & 4.99 & $1.10-22.69$ & & - & & & 3.54 & $1.18-10.61$ & \\
\hline
\end{tabular}

\section{Last sexual intercourse}

Condom use

\begin{tabular}{lllll}
\hline No & - & - & 1.00 & 0.015 \\
\hline Yes & - & - & 0.23 & $0.07-0.75$
\end{tabular}

OR odds ratio, $\mathrm{Cl}$ confidence interval, ' $\mathrm{p}$-value for equality between categories; ${ }^{2}$ Living with relatives, in students' houses or private accommodation. The multivariable models include the significant variables from backwards stepwise procedure. Age and gender (if applicable) included in all models.

boys claimed more substance use related to last intercourse and overall, had same-aged or younger partners, and remained better condom users. Accordingly, girls and boys had differing independent risk factors for chlamydia infection.

\section{Prevalence}

A chlamydia prevalence of $5.7 \%$ was significantly higher than detected in two high school studies in South Norway; $2.0 \%$, and Luxembourg; $1.9 \%$, and in a population based Dutch study in age group 15-19 years; $2.9 \%$ $[6,7,9]$. It is more comparable to $5.2 \%$ detected in a high school study in urban Philadelphia, USA [8]. The high prevalence is in line with the high incidence rates observed in surveillance data, and was to be expected as adolescents living in high prevalence STI areas have significantly increased odds of having a current STI given the available pool of infected partners [16]. A twofold higher prevalence in girls is similar to the results in the above mentioned studies [6-9]. However, 7.3\% is probably a minimum estimate in the female participants as C. trachomatis was detected in FVU samples that are $10 \%$ less sensitive than self-collected vaginal swabs [17].

\section{Socio-demographic characteristics}

Sami/Sami-Norwegian girls having twice the prevalence of ethnic Norwegian girls is in line with a surveillancebased study from 1993 that observed a 6 times higher chlamydia incidence in a Sami municipality in Finnmark compared to the national average [18]. The Sami/ Sami-Norwegian girls more frequently lived outside the family home and reported higher numbers of lifetime sexual partners than the Norwegian girls.

One-third of all participants lived in villages without high schools and had left home to attain further education, and these participants had twice the odds of infection 
compared to those living at home. To our knowledge, this has not been assessed in previous studies. Lack of parental control and detachment from the norms of their community of origin may explain the observed differences.

Maternal educational level $\geq$ college was associated with a twofold higher prevalence in girls, but not in boys. Daughters of higher educated mothers reported more substance use overall and in connection with last intercourse than those with less educated mothers. In contrast, maternal education $\geq$ college level was shown to protect against STIs in a longitudinal study in the USA [19]. The opposing results may reflect cultural differences regarding sexual norms with higher educated mothers in the Nordic countries leaving their daughters more freedom than their American counterparts.

\section{Sexual behaviour}

Condom use at first intercourse was a significantly better predictor of condom use at last intercourse in boys than in girls and can partly explain why condom use at sexual debut was highly protective against chlamydia only in the boys' multivariable model. The poorer predictability of condom use at last intercourse in girls and the finding that more boys than girls used condoms at last intercourse may indicate that girls switch to hormonal contraceptives. Adolescent girls may also lack power to negotiate safe sex with their mostly older partners [5]. Condom use at last intercourse with last partner may be associated with use at previous sexual encounters and thereby explain the protective effect against chlamydia observed in all participants. Most studies show that condom use is associated with reduced chlamydia risk in both women and men [20].

As observed in other studies, number of sexual partners past 6 months was strongly associated with chlamydia infection in girls $[7,21]$. The lack of association in boys could be due to boys frequently over-reporting their number of sexual partners [22].

A higher number of gender-specific C. trachomatis genotypes had previously been detected in girls than in boys in this study population [14]. Based on the genotyping results and most girls reporting older last sexual partners, we concluded that the girls were linked to offschool sexual networks with a different genotype reservoir than same-age boys. As chlamydia infections in surveillance data peak in males aged 20-24 years, we assumed that the older male partners would have higher chlamydia rates than our high school boys. Accordingly, we expected that having an older partner would increase the odds of infection in girls [12]. Due to less than onefourth of girls having last sexual partner same age or younger, the increased infection risk in adolescent girls usually associated with age disparities may have been obscured [23]. To our knowledge, this is the first study to apply high-resolution genotyping as biological support for participants' self-reported sexual behaviour in a population based study. Only $12 \%$ of the boys reported last sexual partner $\geq 1$ year older, but this increased the odds of chlamydia threefold in boys and is similar to the results observed in a recent study [24]. The increase in odds disappeared when adjusting for number of partners past 6 months, indicating that adolescent boys who attract older women may have more opportunities for sex and hence are more sexually active than peers with younger or same-aged partners.

An increased infection risk associated with sexual partners met at a private party, bar or disco could reflect high-risk sexual behaviours and higher chlamydia prevalence among individuals who frequent these venues [23].

Young age at first sexual intercourse is a commonly reported risk factor for chlamydia in adolescents [25]. The Nordic countries traditionally have a higher acceptance of both female and adolescent sexuality than most other Western industrialized countries and are often regarded as representing liberated cultures $[4,26]$. More than $40 \%$ of the sexually active girls in our study reporting sexual debut at $\leq 14$ years may indicate that sexual activity in adolescent girls is accepted in these communities and could explain why early sexual debut did not appear as a risk factor in girls. This is supported by a recent study showing that early coital debut was independently associated with living in Northern Norway [27]. In the boys' crude analysis, early first intercourse was only borderline significant.

The following factors were assumed to be important for the unusually high participation rate in our study: the school-based setting, a test result notification time of only 1-2 days, and class-wise data collection by the same professional study staff.

This is one of few population based studies on prevalent chlamydia infections and associated sexual behaviours in Europe covering both girls and boys aged 15-20 years. We showed that girls and boys accumulate different experiences early in their sexual careers which contribute to the differing chlamydia risk. It confirmed traditional factors commonly associated with chlamydia (female gender, multiple sex partners, older partners, no condom use), but also detected less studied demographic characteristics (residence outside the family home, maternal education) and risk factors (meeting venues for sexual partners).

\section{Limitations}

The study is limited by the cross-sectional design that precludes establishing causality, the self-reported behavioural data, and the lack of statistical power with only 41 chlamydia cases in girls and 18 in boys. Although 
the use of a web-based questionnaire is likely to have reduced social desirability bias [28], sensitive information on sexual behaviour and substance use were selfreported and could be prone to such bias. Finally, our findings may be applicable mainly to the Nordic countries as sexual behaviour has been shown to vary between different cultures and countries [29].

\section{Conclusions and recommendations}

In conclusion, girls this age may be the most costeffective targets for preventive measures and screening due to a high burden of infections and our finding that young girls often make poor choices regarding their sexual health. However, young boys should also be targeted to make them partners in STI control early on. Gender-specific approaches to control chlamydia infections at this particular age may be the best alternative.

\section{Abbreviations}

FVU: First-void urine; STI: Sexually transmitted infection.

\section{Competing interests}

The authors declare that they have no competing interests.

\section{Authors' contributions}

KG conceived and designed the study, collected the data, and drafted the manuscript. GSS and ASF participated in study design. KG and TW performed the statistical analyses. All authors contributed to the interpretation of the results, and revised and approved the manuscript.

\section{Acknowledgements}

The authors are grateful for the support of study nurse Randi Olsen (data collection), Terje Aspenes, Department of Microbiology and Infection Control, University Hospital of North Norway, Tromsø, Norway (laboratory work), and professor Bente Træen, Department of Psychology, University of Troms $\varnothing$, Norway (questionnaire design). Data collection was funded by The Norwegian Directorate of Health (grant number 2009001019) and SpareBank 1 Nord-Norges Medical Research Grant (SNN 20080529). The North Norway Regional Health Authority funded a PhD scholarship for author KG (ID 3117/HST949-10). The funding bodies had no interest in design, collection, analysis, and interpretation of data, or manuscript writing.

\section{Author details}

${ }^{1}$ Department of Microbiology and Infection Control, pb 56, University Hospital of North Norway, Tromsø N-9038, Norway. ${ }^{2}$ Department of Community Medicine, Faculty of Health Sciences, University of Tromsø, Tromsø N-9037, Norway. ${ }^{3}$ Research Group for Host-Microbe Interactions, Department of Medical Biology, Faculty of Health Sciences, University of Tromsø, Tromsø N-9037, Norway.

Received: 10 August 2012 Accepted: 20 November 2012 Published: 22 November 2012

\section{References}

1. European Centre for Disease Prevention and Control: Annual Epidemiological Report on Communicable Diseases in Europe. Stockholm: ECDC; 2010:39-42.

2. Centers for Disease Control and Prevention: Sexually Transmitted Disease Surveillance 2010, Chlamydia. Atlanta: www.cdc.gov/std/stats10/chlamydia. $\mathrm{htm} /$

3. Miller WC, Ford CA, Morris M, Handcock MS, Schmitz JL, Hobbs MM, Cohen MS, Harris KM, Udry JR: Prevalence of chlamydial and gonococcal infections among young adults in the United States. JAMA 2004, 291(18):2229-2236
4. Traeen B, Lewin B, Sundet JM: The real and the ideal; gender differences in heterosexual behaviour among Norwegian adolescents. J of Commun App/ Soc Psychol 1992, 2(4):227-237.

5. Avery L, Lazdane G: What do we know about sexual and reproductive health of adolescents in Europe? Eur J Contracept Reprod Health Care 2008, 13(1):58-70.

6. Hoviskeland A, Lodoen G, Roer R, Jenum PA: Genital Chlamydia among pupils in high school. Tidsskr Nor Laegeforen 2007, 127(16):2077-2079.

7. Mossong J, Muller M, Majery N, Mardaga C, Decruyenaere F, Schneider F: Screening for Chlamydia trachomatis in secondary schools, family planning and occupational health centres in Luxembourg. Sex Transm Infect 2009, 85(6):455-458.

8. Asbel LE, Newbern EC, Salmon M, Spain CV, Goldberg M: School-based screening for Chlamydia trachomatis and Neisseria gonorrhoeae among Philadelphia public high school students. Sex Transm Dis 2006, 33(10):614-620.

9. van Bergen J, Gotz HM, Richardus JH, Hoebe CJ, Broer J, Coenen AJ: Prevalence of urogenital Chlamydia trachomatis increases significantly with level of urbanisation and suggests targeted screening approaches: results from the first national population based study in the Netherlands. Sex Transm Infect 2005, 81(1):17-23.

10. Lee $\mathrm{V}$, Tobin JM, Foley E: Relationship of cervical ectopy to chlamydia infection in young women. J Fam Plann Reprod Health Care 2006, 32(2):104-106

11. Kløvstad H, Aavitsland P: Chlamydia trachomatis infections in Norway, 1986 to 2006, surveillance data. Sex Transm Dis 2009, 36(1):17-21.

12. The Norwegian Institute of Public Health: Genital chlamydial infections in Norway. 2009 [www.fhi.no].

13. The Norwegian Directorate for Education and Training: The School Portal http://skoleporten.udir.no/Gjennomføring/Finnmarkfylke.

14. Gravningen K, Christerson L, Furberg AS, Simonsen GS, Odman K, Stahlsten A, Herrmann B: Multilocus Sequence Typing of Genital Chlamydia trachomatis in Norway Reveals Multiple New Sequence Types and a Large Genetic Diversity. PLoS One 2012, 7(3):e34452.

15. Lund $E$, Melhus M, Hansen KL, Nystad T, Broderstad AR, Selmer $R$, Lund-Larsen PG: Population based study of health and living conditions in areas with both Sami and Norwegian populations-the SAMINOR study. Int J Circumpolar Health 2007, 66(2):113-128.

16. Jennings JM, Taylor R, lannacchione VG, Rogers SM, Chung SE, Huettner S, Ellen JM: The available pool of sex partners and risk for a current bacterial sexually transmitted infection. Ann Epidemiol 2010, 20(7):532-538.

17. Shafer MA, Moncada J, Boyer CB, Betsinger K, Flinn SD, Schachter J: Comparing first-void urine specimens, self-collected vaginal swabs, and endocervical specimens to detect Chlamydia trachomatis and Neisseria gonorrhoeae by a nucleic acid amplification test. J Clin Microbiol 2003, 41(9):4395-4399.

18. Falk ES, Vandbakk O: Declining trends in some sexually transmitted diseases in Norway between 1975 and 1991 with special reference to a Lapp population. Acta Derm Venereol Suppl (Stockh) 1993, 182:15-20.

19. Ford CA, Pence BW, Miller WC, Resnick MD, Bearinger LH, Pettingell S, Cohen M: Predicting adolescents' longitudinal risk for sexually transmitted infection: results from the National Longitudinal Study of Adolescent Health. Arch Pediatr Adolesc Med 2005, 159(7):657-664.

20. Warner L, Stone KM, Macaluso M, Buehler JW, Austin HD: Condom use and risk of gonorrhea and Chlamydia: a systematic review of design and measurement factors assessed in epidemiologic studies. Sex Transm Dis 2006, 33(1):36-51.

21. Goulet V, de Barbeyrac B, Raherison S, Prudhomme M, Semaille C, Warszawski J: Prevalence of Chlamydia trachomatis: results from the first national population-based survey in France. Sex Transm Infect 2010, 86(4):263-270

22. Smith TW: Discrepancies between men and women in reporting number of sexual partners: a summary from four countries. Soc Biol 1992, 39(3-4):203-211.

23. Lee JK, Jennings JM, Ellen JM: Discordant sexual partnering: a study of high-risk adolescents in San Francisco. Sex Transm Dis 2003, 30(3):234-240.

24. Loftus J, Kelly BC: Short-term sexual health effects of relationships with significantly older females on adolescent boys. J Adolesc Health 2012, 50(2):195-197. 
25. Kaestle CE, Halpern CT, Miller WC, Ford CA: Young age at first sexual intercourse and sexually transmitted infections in adolescents and young adults. Am J Epidemiol 2005, 161(8):774-780.

26. Haavio-Mannila E, Kontula O: Sexual trends in the Baltic Sea. Helsinki, Finland: Publication of the Population Research Institute; 2003.

27. Stigum H, Samuelsen SO, Traeen B: Analysis of first coitus. Arch Sex Behav 2010, 39(4):907-914.

28. Turner CF, Ku L, Rogers SM, Lindberg LD, Pleck JH, Sonenstein FL: Adolescent sexual behavior, drug use, and violence: increased reporting with computer survey technology. Science 1998, 280(5365):867-873.

29. Traeen B: Norwegian adolescents' sexuality in the era of AIDS. Empirical studies on heterosexual behaviour. Oslo: University of Oslo; 1993.

doi:10.1186/1471-2334-12-319

Cite this article as: Gravningen et al:: Early sexual behaviour and

Chlamydia trachomatis infection - a population based cross-sectional study on gender differences among adolescents in Norway. BMC Infectious Diseases 2012 12:319.

\section{Submit your next manuscript to BioMed Central and take full advantage of:}

- Convenient online submission

- Thorough peer review

- No space constraints or color figure charges

- Immediate publication on acceptance

- Inclusion in PubMed, CAS, Scopus and Google Scholar

- Research which is freely available for redistribution 